\title{
PENCIPTAAN TOKOH JERRY PADA NASKAH DRAMA THE ZOO STORY KARYA EDWARD ALBEE
}

\author{
I Gusti Lanang Surya Adhityaswara Patra \\ Institut Seni Indonesia Yogyakarta
}

\begin{abstract}
Abstrak: Lakon ini berbicara tentang dampak modernisasi sebuah masyarakat yang membuat orang-orang menderita keterasingan pada kehidupan yang mereka miliki. Tujuan penciptaan tokoh atau karya pemeranan naskah The Zoo Story karya Edward Albee utamanya adalah sebagai media eksplorasi aplikasikan metode pelatihan Stanislavsky dalam tokoh Jerry dalam naskah. Naskah dan karakter tokoh dibahas menggunakan psikoanalisis Freud dan teori struktur dan tekstur. Proses penciptaan tokoh atau pemeranan ini telah terlaksana dengan baik meski terdapat sedikit kendala.
\end{abstract}

Kata kunci : Modernisasi, Optimisme Amerika, Stanislavsky

\begin{abstract}
This playscript talks about the impact of the modernization of a society that makes people suffer from alienation to their lives. The purpose of character creation on this "The Zoo" playscript by Edward Albee is primarily as an exploration medium to apply Stanislavsky's training methods in Jerry's character. The playscript and characters are discussed using Freud's psychoanalysis and theories of structure and texture. The character creation process has been carried out well despite a few obstacles.
\end{abstract}

Key words: modernization, American Optimism, Stanislavsky

\section{Pendahuluan}

Joseph Raymod McCarthy (19081957) adalah seorang senator dari partai Republik yang berasal dari Wisconsin. Ia pernah memimpin penyelidikan terhadap sejumlah orang yang diduga terlibat dalam kegiatan partai komunis. Presiden Harry S. Truman dan Dean Acheson pun dituduh demikian. Pada mulanya, tuduhan kepada Presiden Truman dianggap biasa, sebab Truman datang dari partai Demokrat. Akan tetapi, McCarthy mulai merepotkan tatkala ia juga sama-sama dari partai Republik. Serangan gencar juga diarahkan kepada Angkatan Darat Amerika. Akan tetapi, Angkatan Darat Amerika, melancarkan serangan balik dengan membuktikan bahwa tuduhannya tidak benar. Ia akhirnya jatuh dari singgasana politik Amerika tatkala rakyat Amerika menuduhnya sebagai seorang penipu. Amerika adalah negara pesimisme hidup tak punya akar, pengaruh absurd tidak begitu banyak. Pada tahun 1950-an Amerika sedang gencar dengan gerakan antikomunis yang dikenal dengan gerakan McCarthysm (Soemanto, 2002).

Setelah itu gerakan antikomunis muncul pada tahun 1950-an. Gerakan tersebut erat kaitannya dengan pertentangan Amerika kepada dan sekutunya melawan Uni Soviet dan sekutunya (Sumanto, 2002).

Itulah yang menyebabkan teater di Amerika pada tahun 1950-1970an terkena dampak kekecewaan situasi poitik tersebut. Festival tidak dapat berjalan dengan mulus karena hidup sudah diluar kontrol dan perang dingin sudah membekukan semangat hidup masyarakat Amerika (Soemanto, 2002). 
Hal inilah yang membuat keadaan warga Amerika menjadi pesimis dalam menjalani hidup, termasuk juga pada perkembangan teater di Amerika. Hal ini yang membuat dramawan seperti Edward Albee menuliskan sebuah naskah tentang krisis eksistensi negaranya.

Edward albee adalah seorang penulis naskah yang berasal dari Amerika. Naskah yang pertama kali diciptakan oleh Edward Albee adalah The Zoo Story pada tahun 1958 (Soemanto, 2002).

Lakon ini berbicara tentang dampak modernisasi sebuah masyarakat yang membuat orang-orang menderita keterasingan pada kehidupan yang mereka miliki. Selain itu lakon ini juga berbicara menyerang landasan optimisme Amerika (Eslin, 2008). Selain itu, dalam lakon ini beberapa paham filsafat juga bisa ditemukan dalam naskah ini. Seperti misalnya filsafat eksistensialisme berarti adanya, dan dibedakan dari esensi yang berarti hakikat (Panjaitan, 1996).

Meskipun The Zoo Story kurang laku di Amerika, sehingga pementasan pertama dilakukan di Berlin Jerman pada tahun 1958, akhirnya The Zoo Story pun dipentaskan di Broadway pada tanggal 14 januari 1960 (Soemanto, 2002).

Dalam naskah The Zoo Story mempunyai 2 tokoh yang berlawanan secara status sosial yaitu Jerry dan Peter. Jerry adalah tokoh yang memiliki pola pikir yang berubah-ubah, dimana setiap bahasan dialognya banyak perubahan pada pikirannya, dibuktikan dengan bentuk yang ia bahas pada Peter. Jerry juga adalah tokoh yang kesepian dan tidak mempunyai seorang keluarga. Dibuktikan pada dialog-dialog Jerry dimana Jerry pada awalnya membicarakan soal kebun biantang, lalu setelah itu Jerry bertanya tentang kehidupan Peter, yang ketiga Jerry membicarakan tentang kehidupannya senidiri, dan pada akhirnya Jerry memilih untuk membunuh dirinya dengan media Peter, artinya aktor memainkan tokoh Jerry mempunyai kesulitan sendiri yaitu dimana aktor harus memainkan emosi dan pola pikir yang dimiliki oleh Jerry.

Selain itu Jerry juga memiliki pola pikir yang tidak biasa dengan pemikiran umunya, yaitu dimana Jerry berfikir bahwa Jerry tidak memiliki pekerjaan, tidak mempunyai istri, dan berfikir tentang ideologinya sebagai manusia. Jerry bisa disebut orang eksistensi menurut Kierkegaard yaitu dimana individu yang eksis, adalah pribadi-pribadi yang sadar bukan sekedar bagian suatu kerumunan, angka-angka dalam suatu kelompok atau benda-benda dalam suatu kumpulan (Martin, 2001).

Selain Eksistensialisme, ada juga teori Karl Max yang terdapat dalam naskah ini, misal saat pembicaraan Jerry tentang kelas sosial. Dalam teori Karl Max, kelas sosial adalah bagian dari paham Karl Max, yang artinya kelas sosial adalah golongan sosial dalam tatanan masyarakat yang ditentukan oleh posisi tertentu dalam proses produksi (Magnis-Suseno, 2000).

The Zoo Story memiliki kerumitan tersendiri yang dimana aktor harus benarbenar fokus untuk menciptakan tokoh Jerry yang mempunyai masalah sehingga ia memilih untuk mati. Harapan dalam pertunjukan ini dapat dinikmati oleh penonton dan dapat mengambil pesan moral yang terkandung dalam drama The Zoo Story karya Edward Albee ini.

Adapun tujuan penciptaan karya ini adalah untuk:

a. Memerankan tokoh Jerry dalam lakon The Zoo Story karya Edward Albee.

b. Mengaplikasikan metode pelatihan Stanislavsky dalam tokoh Jerry dengan naskah The Zoo Story karya Edward Albee.

\section{Teori}

Landasan teori digunakan untuk mendukung tulisan karya Tugas akhir sekaligus menjadi landasan untuk merancang karakter Tokoh. Landasan teori diharapkan dapat memperkuat gagasan 
perancang yang bersifat ilmiah dalam rumusan masalah yang dihadapi.

Dalam memahami tokoh Jerry dalam lakon The Zoo Story memerlukan teori yang tepat untuk bisa menganalisisnya. Teori yang digunakan adalah teori psikoanalisis Sigmund Freud dan teori Struktur dan Tekstur. Psikoanalisis termasuk di dalam golongan ilmu jiwa, bukan ilmu jiwa kedokteran dalam arti kata lama, bukan juga tentang ilmu jiwa tentang proses penyakit jiwa, tapi sematamata ilmu jiwa biasa (Hall, 2017).

Psikoanalisis mempuyai 3 sistem yang penting yaitu Id, Ego, Superego. Dalam diri manusia mempunyai jiwa yang sehat, ketiga sistem ini merupakan satu susunan yang bersatu dan harmonis. Id adalah suatu alat refleksi yang segera melepaskan melalui saluran -saluran motoris setiap ransangan sensoris yang tiba padanya. Ego adalah hubungan timbal balik antara seseorang dengan dunia memerlukan pembentukan suatu sistem rohaniah baru. Sedangkan Superego adalah cabang keadilan dari kepribadian. Ketiga sistem ini tidak dipisahkan (Hall, 2017).

Teori Struktur dan Tekstur menurut Kernodle (dalam Dewojati, 2012). Struktur adalah bentuk drama dalam pementasan, sedangkan Tekstur adalah apa yang dilakukan langsung oleh pengamat. Adapun di dalam Struktur terdapat tiga bagian yaitu : Plot, Tema, dan Karakter, sedangkan Tekstur ada tiga bagian yaitu Dialog, Mood, dan Spectacle.

Setelah teori untuk memahami tokoh Jerry, sekarang ialah teori untuk memerankan tokoh Jerry. Landasan teori yang digunakan untuk memerankan tokoh Jerry adalah acting oleh Stanislavsky yang mengatakan keindahan, daya tarik dan pesona tidaklah terletak pada dialog, tetapi terletak dalam arti yang terletak di belakang dialog-dialog tersebut, di dalam jeda atau pause, dalam pandangan para aktor dalam cara mempermainkan emosi (Stanislavsky, 2006).

Aktor menggunakan segala yang ada pada diri, mulai dari tubuh, vokal serta sukma seorang aktor sangat penting untuk menunjang perfoma seorang aktor di atas panggung, serta mampu menghidupkan karakter pada tokoh yang akan dimainkan oleh aktor. Tanpa diri si pemeran sendiri, aktor tidak bisa mengeskpesikan serta menjadi tokoh yang dimainkan. Untuk mencapai tujuan tersebut, aktor harus merancang tokoh yang akan dipentaskan.

Hakekat seni peran adalah meyakinkan (make believe). Jika berhasil meyakinkan penonton bahwa apa yang telah dilakukan aktor adalah benar, paling tidak, itu sudah cukup (Riantiarno, 2011). Keaktoran menurut Constantin Stanislavsky adalah usaha-usaha untuk penciptaan sebuah filsafat untuk para aktor dalam mencoba memberikan tafsiran seni berperan (Iswantara, 2016).

Tokoh yang dimainkan oleh aktor juga mempunyai kehidupan yang sama seperti manusia. Mempunyai karakter (suara, pikiran dan perasaan). Untuk dapat menciptakan rancangan tokoh yang baik, maka diperlukan menganalisis naskah terlebih dahulu. Dalam menganalisis naskah perlu melihat karakter tokoh yang akan dimainkan. Dialog adalah salah satu kunci untuk mendapatkan karakterkarakter tersebut. Satu kata di dalam dialog dapat dianalisis untuk mencapai karakter tokoh.

\section{Metode Penciptaan}

Metode dalam kamus besar bahasa Indonesia, metode adalah cara teratur yang digunakan untuk melaksanakan suatu pekerjaan agar tercapai sesuai dengan yang dikehendaki. Seorang aktor harus mempunyai cara untuk menciptakah tokoh yang diinginkan.

Sebelum aktor menciptakan tokoh, aktor harus memilih naskahnya terlebih dahulu. Selanjutnya aktor memilih peran yang akan diciptakan tokohnya. Aktor memilih naskah The Zoo Story karya Edward Albee dengan tokoh Jerry.

Dalam naskah The Zoo Story, dengan tokoh Jerry yang dimana Jerry adalah tokoh yang memiliki krisis eksistensi 
akibat gerakan antikomunis yang ada di Amerika. Jerry berjalan kaki setelah dari kebun binatang dan menemukan seseorang yang bernama Peter. Ketika berbincang dengan Peter, Jerry bercerita banyak tentang kehidupannya yang sangat kelam. Jerry adalah tokoh yang belum menikah dan tinggal disebuah kontrakan dan mempunyai anjing gila, berbeda dengan Peter yang sudah memiliki istri dan anak yang mempunyai kucing dan parkit, televisi dan kehidupan yang layak. Seorang aktor harus mampu menciptakan tokoh Jerry.

Metode yang digunakan aktor ialah yang pertama memilih naskah The Zoo Story karya Edward Albee. Di dalam sebuah drama memiliki sebuah tokoh yang diciptakan oleh penulis, dan aktor memilih salah satu tokoh tersebut yaitu Tokoh Jerry dalam askah The Zoo Story.

Untuk memerankan sebuah tokoh diperlukan teori atau alat untuk memahami atau menganalisis sebuah karakter tokoh. Aktor menggunakan teori Psikoanalis untuk memahami atau menganalisis tokoh Jerry dalam naskah The Zoo Story. Setelah memahami atau menganilisis tokoh akan menghasilkan analisis tokoh Jerry dan aktor memerankan tokoh tersebut dengan menggunakan akting dari Stanislavsky tetapi dengan gaya pertunjukan Eksistensialisme dan akan menghasilkan ruang reflektif dan untuk menjadi bahan yang kritis untuk penonton.

Artinya dalam penciptaan sebuah tokoh memerlukan sebuah metode untuk aktor agar penciptaan bisa dikatakan berhasil dalam menciptakan tokoh Jerry.

\section{Pembahasan}

Konsep Pemeranan

Hakekat seni peran adalah meyakinkan (make believe).Jika berhasil meyakinkan penonton bahwa apa yang telah dilakukan aktor adalah benar, paling tidak, itu sudah cukup (Riantiarno, 2011). Aktor harus memiliki tahapan-tahapan untuk mencapai target untuk menciptakan sebuah karakter drama. Salah satu metode
Stanislavsky adalah untuk mendorong aktornya mengkaji detail-detail dunia "yang lain" dari naskah melibatkan susunan pertanyaan tentang penokohan mereka yang ketika diteliti dan dijawab membangun apa yang ia sebut sebagai "kondisi yang tersedia" (Mitter, 2002).

Stanislavsky menganjurkan aktor untuk melakukan sesuatu di atas panggung dengan kesadaran. Artinya di setiap menit dalam kehidupan, manusia harus merasakan sesuatu. Hanya orang mati yang tidak lagi merasa. Kita harus tahu apa yang kita rasakan di atas panggung (Stanislavsky, 1980).

Aktor juga tidak boleh bermain secara klise, dalam arti aktor harus menciptakan suara, gestur, pikiran, dan perasaan tokoh. Karena sering terjadi, bahwa aktor yang paling berpengalaman sekalipun mempersiapkan dirumah dan kemudian membawanya ke panggung sesuatu yang bukan saja tidak penting, tapi juga tidak penting bagi pemeranan mereka (Stanislavsky, 1980).

\section{Proses Penciptaan}

Proses berlatih adalah dimana seorang aktor berlatih untuk menciptakan sebuah tokoh. Aktor harus mencapai target-target yang telah dirancang agar dalam proses latihan, mendapatkan hasil yang memuaskan.

Dalam naskah The Zoo Story ini, Jerry adalah seseorang penganut paham eksistensialis, sebagamana yang telah ditulis di BAB II. Jerry adalah sosok yang membutuhkan penghargaan keberadaannya dengan melalu mengajak berbicara pad seorang yang duduk sendiri yang bernama Peter. Adapun aktor harus melalui proses latihan sebagai berikut :

1. Berlatih Mengolah Tubuh

Sebelum menciptakan sebuah tokoh, aktor harus menyiapkan tubuh dengan baik agar penciptaan tubuh tokoh Jerry bisa berlangung dengan baik. Otot-otot di dalam tubuh dibuat untuk menjadi lebih kencang dan lebih lentur agar penciptaan gestur tokoh Jerry bisa tercipta dengan 
efektif. Dalam latihan aktor, mengencangkan dan melenturkan pergerakan mata, alis, pipi, dahi, mulut, leher, lengan, tangan, siku, jari, dada, perut, pinggang sampai ke kaki. Hal ini dilakukan utuk menyiapkan kondisi aktor lebih siap.

\section{Berlatih Vokal}

Selain tubuh, aktor juga mempunyai vokal yang digunakan untuk mengucapkan dialog. Berlatih vokal digunakan untuk mencapai vokal yang keras dan bisa berucap dengan jelas atau artikulasi dengan jelas.

Adapun yang dilatih aktor yaitu berlatih nafas dan berlatih tekhik pengucapan. Aktor melatih nafas dengan cara mengontro nafas dengan baik, agar vokal dapat diucapkan dengan sesuai kebutuhan. Sedangkan berlatih tekhnik pengucapan, yaitu dimana aktor berlatih dengan mengucapkan huruf a sampai $\mathrm{z}$ dengan kencang dan tepat.

\section{Reading}

Seorang aktor sebelum menciptakan sebuah tokoh, maka aktor harus mengetahui bagaimana cerita naskah The Zoo Story. Selain itu, dalam tahap ini, aktor juga menentukan,membahas gagasan tentang naskah The Zoo Story.

Saat membaca naskah, aktor dapat mengerti bagaimana alur, tema, dan penokohan, seperti yang sudah dijelaskan di BAB II.

Reading dilakukan dengan membaca bersama aktor yang memerankan tokoh Peter agar saling mengerti cara pengucapannya.

Aktor membaca dengan nada yang datar tanpa interpretasi terlebih dahulu, agar aktor tidak terpengaruh dengan interpretasi awal.

\section{Diskusi Gagasan}

Pada tahap ini, aktor melakukan diskusi digunakan unutk mencari tahu gagasan apa yang terkandung dalam naskah. Selain gagasan, aktor juga mendiskusikan tentang penulis yaitu Edward Albee.

Aktor mengalami kesulitan dengan gagasan ini. Pada bulan awal proses aktor mendapatkan diskusi tentang naskah The Zoo Story membicarakan tentang Rasisme kulit hitam dan kulit putih yang ada di Amerika pada taun tersebut. Setelah berdiskusi, aktor mendapatkan gagasan naskah ini berbicara antikomunis di Amerika tetapi dengan gaya pertunjukan absurd serta penciptaan karakter yang aneh.

Setelah mengalami banyak evaluasi dan diskusi, aktor pun memutuskan untuk memilih gagasan tentang eksistensialis yang ada pada naskah tersebut. Ada dua gagasan yang terdapat dalam teks tersebut yaitu tentang eksistensialis menururt Kiekergad dan eksistensialis menurut Jean P. Sartre.

Gagasan yang ingin ditunjukan oleh penulis ialah tentang keberadaan tokoh Jerry yang tidak memiliki teman,keluarga maupun kekasih. Jerry juga adalah tokoh yang eksistensialis, artinya Jerry ingin diakui keberadaannya oleh Peter. Jerry juga adalah tokoh yang bebas, karena ia lari dari rumah susun yang membuat dia merasa tidak nyaman, selain itu Jerry merencakan soal kematiannya.

Jerry adalah tokoh yang tidak memiliki keluarga, teman maupun kekasih, artinya Jerry adalah tokoh yang sendiri. Ketika ia sampai di West Side, New york, dia diganggu oleh Nyonya pemilik rusun dan seekor anjingnya. Tetapi ia menyadari bahwa hanya anjing tersebut yang mengakui keberadaanya. Anjing itu menggigit salah satu kaki Jerry. Saat itu Jerry memututskan untuk membunuhnya. Tetapi karena tidak mati, anjing itu dan Jerry akhirnya mendapatkan suatu hubungan yang lebih baik. Setelah itu Jerry mencoba untuk melakukannya lagi pada seorang Peter yang duduk di taman.

Jerry sebenarnya bermaksud untuk mengemukakan ideologinya sebagai manusia yang berada kepada Peter. Karena Peter tidak paham dengan maksud Jerry, 
akhirnya Jerry memutuskan untuk membunuh diri sebagai tanda bukti bahwa manusia butuh eksistensinya.

\section{Motivasi}

Motivasi digunakan dalam penciptaan sebuah tokoh, dimana motivasi terkandung dalam setiap dialog, bahkan setiap kata. Aktor memilih motivasi dimana bahwa Jerry adalah tokoh yang kesepian, tokoh yang memiliki pemikiran bebas, dan tidak takut mati. Motivasi tersebut menjadi bagian yang sangat kuat dari tokoh Jerry.

Aktor sebagai pencipta harus melakukan sesuatu yang mempunyai arti di atas panggung. Setiap gerak,kedipan mata,nafas itu adalah bagian dari akting. Maka apapun yang terjadi di atas panggung harus mempunyai tujuan (Stanislavsky, 1980).

Aktor melakukan anilisis pada pikiran tokoh yang terdapat pada teks. Untuk mendapatkan hasil motivasi tokoh, aktor mencari tahu tentang arti dialog yang berada di teks dengan cara menggunakan metode "interogasi" yaitu dimana aktor mempertanyakan setiap dialog yang muncul dengan pertanyaan "Apa,Siapa,Bagaimana,Dimana,Kapan,Me ngapa". Artinya aktor mencari tahu setiap suku kata yang terdapat pada dialog tersebut.

Tidak hanya itu, aktor juga mencari tahu tentang jembatan pikiran dari dialog satu ke dialog lain. Artinya aktor mencari kemungkinan lain dengan mencari jembatan pikiran tersebut.

Adapun aktor juga mencari respon pikiran, yaitu dimana ketika lawan main sedang berdialog, maka aktor harus menciptakan pikiran sera respon yang dikeluarkan lewat tubuh.

\section{Penciptaan Suara}

Suara adalah bagian materi seorang aktor. Sebagai seorang aktor juga harus menciptakan suara tokoh Jerry. Aktor harus membuat penonton dapat mendengar dan memahami apa yang patut diperhatikan (Stanislavsky, 2008). Dalam hal ini aktor membagi 2 bagian untuk menciptakan suara yaitu : nada dasar, dan karakter suara.

Pada tahap ini, aktor mencoba untuk mencari refrensi pola dialog orang-orang amerika di film yang dimainkan oleh John Garfield. Aktor menemukan bahwa perbedaan cara ucap orang amerika tahun saat ini dengan tahun 1950an sangatlah berbeda. Pada tahun 19950an orang-orang Amerika cendrung mengayunkan intonasiintonasi yang diucapkan, bahkan cara bicara mereka seperti orang dibagian Indonesia timur. Sedangkan orang Amerika saat ini lebih datar dibandingkan dengan tahun 1950an, tetapi orang Amerika saat ini kebanyakan sangatlah ekspresif dalam berucap maupun berekspresi. Maka aktor pun mencoba untuk melatihkanya setiap hari, bahkan dalam keadaan tertentu.

\section{a. Nada Dasar}

Dalam hal ini, aktor menentukan nada dasar tokoh ciptaan. Jerry dalam hal ini sangat gelisah untuk menceritakan apa yang terjadi pada Jerry dan berencana membunuh dirinya melewati Peter. Artinya nada dasar yang diciptakan aktor adalah nada yang meninggi. Hal ini dipertegas juga karena Jerry ingin bercerita dengan Peter tentang kejadian yang di alaminya. Nada dasar yang tinggi juga menunjukan bahwa emosional Jerry sedang tidak stabil. Karena Jerry juga tidak mempunyai orang tua yag menjadi panutannya, maka secara emosional, Jerry mudah sekali sensitif, marah. Hal ini juga ditunjukan dengan adanya bukti bahwa Jerry berencana untuk membunuh dirinya. Tokoh Jerry tidak berfikir seperti manusia pada umumnya yang berfikir tentang bagaimana cara mempertahankan dirinya dalam hidup, tapi Jerry berfikir tetnag bagaiamana menjadi manusia yang berada dan memiliki fungsi sebagai manusia.

b. Karakter Suara

Selain intonasi suara, penting juga untuk mengetahui karakter suara tokoh Jerry. Tokoh Jerry mempunyai 
pengalaman pribadi yang sangat menyakitkan. Jerry juga bukan seorang perokok, hanya saja dia sering meminum beer. Artinya aktor dalam mecipta karakter suara akan menggunakan karakte suara yang tidak banyak karakter berat, tetapi menjadi karakter yang menggunakan suara yang sedikit tertahan, karena pengalaman pribadinya yang menyakitkan.

Banyak sekali perubahan karakter suara yang dilakukan, artinya saat dalam proses penciptaan, aktor mengalami banyak perubahan karakter suara.

Pada bulan Januari, aktor menciptakan suara dengan sedikit meninggi dengan motivasi Jerry senang bahwa baru saja dari kebun binatang. Setelah mengalami proses pemilahan gagasan, pada bulan februarimaret, aktor menggunakan karakter suara yang rendah dan bahkan hampir tak terdengar karena pada waktu itu, aktor membuat motivasi bahwa Jerry dalam keadaan depresi dan memilih jalan untuk buuh diri. Tetapi setelah mengalami banyak diskusi, akhirnya aktor memilih karakter suara yang tinggi dengan alasan bahwa Jerry adalah tokoh bebas, yang dimana pada saat bertemu dengan Peter, Jerry seakan menyembunyikan pikiranpikiran tentang ketidaksetujuannya dengan penyikapan Peter sebagai seorang kepala keluarga. Maka aktor memilih nada yang tinggi sebagai tanda kekesalan terhadap Peter dan terhadap dunia yang dihadapi Jerry.

\section{Penciptaan Tubuh}

Selain suara, materi seorang aktor adalah tubuh. Tubuh adalah organ yang bisa dilihat dengan mata oleh manusia. Jerry adalah tokoh eksistensialis, dan juga adalah tokoh yang mengemukakan kebebasan seorang manusia. Dalam proses, aktor menciptakan tubuh seperti tokoh dibagi menjadi 3 bagian yaitu : bagian atas, bagian tengah, dan bagian bawah.

a. Bagian Atas

Bagian atas adalah bagian kepala seorang aktor. Jerry adalah tokoh yang pandai menganalisa seseorang, dan mengerti tentang psikologi, khususnya Sigmund Freud. Artinya penciptaan tokoh Jerry pada bagian kepala akan dibuat menjadi mata yang tajam dalam melihat sesuatu dan menganalisa.

Jerry tidak hanya pintar dalam menganalisa, dia mampu untuk menyembunyikan apa yang akan ia lakukan. Maka mata Jerry akan banyak kedipan dari biasanya pada dialog-dialog tertentu. Seperti yang telah dijelaskan pada buku psikologi yang mengatakan bahwa mata adalah gerbang jiwa, dan jendela hati.

Pada saat berbohong, mata akan selalu berupaya untuk melihat ke arah lain (Putra, 2013).

Pada bagian mata juga diciptakan sedikit melebar, dikarenakan bahwa mata yang melebar dan tajam menunjukan bahwa Jerry terbiasa menilai sesuatu dengan ilmu psikologinya.

Selain itu alis tokoh Jerry sering sekali diciptakan seperti sedang memikirkan sesuatu ketika Peter berbicara, artinya Jerry sedang menilai apa yang dilakukan oleh Peter secara penilaian Psikologi.

Pada bagian hidung, aktor menciptakan pengeluaran nafas yang sedikit cepat pada bagian awal, dikarenakan Jerry baru saja berjalan jauh. Setelah itu pada bagian pertengahan Jerry juga mengalami kelelahan, maka aktor mngatur nafas dengan cepat diringi dialog yang diucapkan.

b. Bagian Tengah

Jerry ketika dikebun binatang, mencoba untuk berbicara dengan Peter, walaupun Peter tidak menerimanya secara halus. Artinya aktor akan menciptakan tangan tokoh Jerry banyak membuka, yang artinya Jerry mencoba untuk mengajak Peter berkomunukasi.

Jerry dalam hal ini mencoba untuk melawan ideologi yang ada di dalam pikiran Peter. Ideologi yang dimaksud adalah bahwa Jerry ingin dianggap keberadaaanya sebagai manusia oleh Peter. Maka dari itu, Jerry mencoba beruasaha mengajak Peter untuk berkomunikasi. 
Pada bagian dada, sedikit dicondongkan dengan alasan aktor menemukan narasi pad naskah asli yang mengatakan bahwa Jerry sebelumnya kekar sudah menjadi sedikit gemuk. Pada bagian ini, artinya aktor tetap membusungkan dadanya dengan alasan bahwa setiap orang yang melatih ototnya atau fitnes pasti mengalami dada yang membusung, karena pembiasaan saat fitnes.

Aktor mencoba melakukannya diluar latihan bersama team. Aktor melakukanya setiap hari agar pembiasaan tubuh Jerry tersebut menempel pada diri aktor.

c. Bagian Bawah

Sebelum dari kebun binatang, Jerry berjalan dari Washington Square ke kebun binatang. Jarak dari Washington Square ke kebun binatang adalah 4,506 kilometer atau 2,8 mil. Jika berjalan kaki berkisar sekitar 58 menit. Artinya tokoh Jerry adalah tokoh yang memiliki kaki yang kuat, dan Aktor menciptakan kaki dengan otot yang menegang.

Aktor juga menciptakan jalan kaki seperti kelelahan dalam berjalan, seperti ayunan kaki menjadi lebih tak terarah. Artinya Jerry mengalami keletihan dalam berjalan, bahkan ketika bertemu dengan Peter pun, Jerry memilih untuk berdiri sampai ia bercerita tentang anjing yang tinggal dirumah susun yang ia tempati.

Pada tahap ini, aktor melakukan jalan sesuai dengan jarak yang sudah ditentukan. Aktor berjalan kaki dari rumah kos sampai mall maliobor untuk bertemu dengan lawan main yang memainkan tokoh Peter dengan harapan dapat merasakan langsung berjalan kaki yang jauh. Maka aktor menyimpulkan bahwa Jerry mengalami kelelahan saat berjalan kaki,walaupun Jerry pernah mengalami latihan-latihan otot seperti fitnes. Aktor mendapatkan waktu sekitar satu jam empat puluh lima menit untuk menempuh jarak yang begitu jauh.

Langkah kaki yang diciptakan aktor pun juga mengalami pemilihan, artinya disini aktor menciptakan berdasarkan analisa yang sudah dijelaskan, bahwa Jerry adalah tokoh yang cerdas,artinya Jerry yakin pada setiap keputusan. Maka aktor menciptkan jalan yang pasti tidak terbatabata.

d. Konsenterasi

Konsentrasi dilakukan untuk menjaga pikiran,tubuh,suara yang sudah diciptakan oleh aktor sesuai dengan kebutuhan. Dalam hal ini, aktor mendengarkan dan menganalisa suara apa saja yang terdengar. Hal ini dilakukan untuk menjaga keadaan pikiran tetap berlangusng, artinya otak tidak dalam keadaan kosong.

Tidak hanya mendengar, aktor melakukan analisa dengan cara melihat. Setiap gerakan tubuh seseorang yang terlihat, maka aktor mencoba untuk menganalisa, agar tetap terjadinya konstrasi pada saat keadaan berlatih maupun tidak berlatih.

Aktor dalam hal ini mengalami kesulitan, artinya konsentrasi sangatlah penting dalam latihan seorang aktor diatas panggung. Analisa yang detail, fisik yang prima adalah kunci agar aktor tetap fokus.

Perbuahan interpretasi terhadap gagasan serta terhdap karakter pun menjadi kesulitan bagi aktor. Beberapa mengalami perubahan interpretasi tersebut membuat aktor harus memilih interpetasi yang tepat.

e. Evaluasi

Pada tahap ini aktor harus berani memeriksa permainan aktor sendiri dan permainan lawan main. Selama bulan Januari-sampai bulan Juni aktor tidak menggunakan sutradara, dikarenakan aktor memilih menciptakan karakter terlebih dahulu sebelum sutradara memberi pengarahan atas komposisi dan lain-lain.

Evaluasi sering dilakukan pada saat latihan telah usai, setelah itu aktor memperbaiki evaluasi-evaluasi yang sudah dicatat baik menurut pemain lain, dan menurut diri sendiri.

f. Perubahan Interpretasi

Perubahan interpretasi sering terjadi pada penciptaan tokoh Jerry serta pemilihan gagasan yang akan diambil. 
Perubahan interpretasi ini dilakukan agar analisa-analisa yang sudah disepakati bisa lebih berkembang. Artinya analisa tersebut tidak akan pernah selesai. Dalam hal ini aktor mencapai kehidupan diatas panggung melalui gagasan Edward Albee. Maka dari itu aktor memerlukan perubahanperubahan interpretasi.

Perbuahan interpretasi sering dilakukan saat mencoba membaca naskah, lalu kembali memeriksa gagasan yang sudah ada. Artinya setiap saat aktor memikirkan interpretasi.

\section{g. Pembiasaan}

Ketika sudah menemukan pikiran, perasaan, tubuh dan suara tokoh, maka aktor mencoba untuk membiaskannya. Aktor sering mebiasakan ketika saat berjalan kaki sendiri, berdialog sendiri di dalam kamar, mencoba untuk sering menilai orang. Hal-hal seperti itu dilakukan aktor supaya saat pementasn tidak menjadi sangat kaku.

\section{Simpulan}

Pertunjukan teater adalah sebuah pertunjukan yang membutuhkan kerja kolektif dari aktor, sutradara, penata artistik, penata musik. Artinya pertunjukan teater tidak bisa dilakukan oleh aktor saja. Maka diperlukan sutradara yang menjalin pertunjukan, juga diperlukan penata artisitk yang menciptakan artistik yang sesuai dengan kebutuhan gagasan dan kebutuhan panggung.

Aktor yang berhasil adalah aktor yang bisa mencapai target yang telah ditentukan, dan bisa bermain seperti kebutuhan naskah,gagasan dan panggung. Artinya aktor juga harus melepaskan karakter diri yang menempel setiap saat. Aktor harus memulai melatih dengan kepribadian tokoh Jerry dalam naskah The Zoo Story karya Edward Albee.

The Zoo Story adalah drama yang berisikan tema tentang eksistensialisme, dimana eksistensialisme adalah tentang keberaddan dua tokoh yang sangat berbeda pada naskah tersebut. Peter adalah tokoh yang memiliki kehidupan yang mewah, tetapi ia memiliki krisis eksistensi pada dirinya, yaitu dimana ia terkekang oleh aturan keluarganya. Peter pun juga sebenarnnya mengingkan seorang anak laki-laki tetapi istri dari Peter memilih untuk mempunyai anak permpuan. Tidak hanya itu Peter juga sebenarnya menyukai anjing, tetapi karena menuruti kemauan anak dan istrinya, maka Peter pun memilih untuk memiliki kucing dan burung parkit.

Berbeda dengan Peter, Jerry memiliki hidup yang berbanding terbalik dengan Jerry. Tetapi dalam hal ini, Jerry berusaha untuk memperjuangkan ekistensinya sebagai manusia kepada Peter. Peter yang menolak itu, akhirnya membuat Jerry memutskan untuk merencanakan pembunuhan atas dirinya dengan melalui Peter.

Jerry adalah sosok yang sangat mengedepankan eksistensinya sebagai manusia, dimana ia menginkan kebebasan dari hidup yang membuat ia terpenjara. Jerry adalah tokoh yang tidak mempunyai tempat tinggal, keluarga bahkan seorang kekasaih. Jerry juga hidup di tempat yang sangat menjijikan bagi dirinya dimana ia tinggal di West Side, New York. Ditempat itulah ia menyadari bahwa manusia itu harus memiliki eksistensi. Banyak hal yang sudah dilaluinya di tempat dimana ia tinggal itu. Mulai dari ia disukai oleh nyonya pemilik rusunnya, dan akhirnya ia melakukan hubungan sexual dengan nyonya yang dianggapnya gembrot itu.

Selain itu anjing yang selalu mengganngunya yang membuat ia tersadar bahwa, anjing itulah yang satu-satunya menganggap keberadaan Jerry sebagai manusia. Akhirnya Jerry memutuskan untuk pergi dari rumah menuju jalan Fifth Avenue dan berjalan ke utara sampai bertemu dengan Peter.

Saat dikebun binatang itu, banyak ideologi eksistensialis yang tertanam pada Jerry. Jerry yang menyadari bahwa Peter tidak mau mengikuti ideologi, akhirnya memutuskan diri untuk membunuh diri lewat Peter, sebagai tanda bukti bahwa 
manusia harus berada, dan memiliki eksistensi sebagai mansia.

Proses penciptaan tokoh Jerry banyak mengalami kendala, artinya disetiap proses kendala itu yang membuat proses akan menjadi lebih baik, juga semua pendukung.

\section{Daftar Pustaka}

Dewojati, C. (2012). Drama Sejarah, Teori, dan Penerapannya. Javakarsa Media

Eslin, M. (2008). Teater Absurd. Mojokerto : Pustaka Banyumili

Hall, C. (2017). Naluri Kekuasaan Sigmund Freud, Jakarta: PT Buku Seru

Iswantara, N. (2016). Drama Teori Dan Praktik Seni Peran. Yogyakarta : Media Kreatifa.

Martin, V. (2001). Filsafat Eksistensialisme (Kierkegaard, Sartre, Camus), Yogyakarta: Pustaka Pelajar.

Magnis-Suseno, F. (2000). Pemikiran Karl Max Dari Utopis Ke Perselisiha Revisionisme, Jakarta: PT. Gramedia Pustka Utama.

Mitter, S. (2002). Stanislavsky, Brecht, Grotowsky, Brook, Sistem Pelatihan Lakon, Yogyakarta.

Panjaitan, O. (1996). Manusia Sebagai Eksistensi, Jakarta: Yayasan Sumber Agung.
Putra, E. D. (2013). Rahasia Bahasa Tubuh. Jakarta : Titik Media Publisher Riantiarno, N. (2011). Kitab Teater 'Tanya Jawab Seputar Seni Pertunjukan. Jakarta: PT. Gramedia Widiasarana Indonesia.

Stanislavsky, K. (1980). Persiapan Seorang Aktor. terjemahan Asrul Sani. Jakarta : PT. Bastela Indah Prinindo

Stanislavsky, K. (2006). My Life In Art, terjemahan G. Ivanov Munjiev. Malang: Pustaka Kayutangan.

Stanislavsky, K. (2008). Membangun Tokoh. terjemahan Slamet Rahardjo Djarot, Jakarta : Kepustakaan Populer Gramedia

Sumanto, B. (2002). Godot di Amerika dan Indonesia. Jakarta : PT. Grasindo. 